\title{
A Mysterious Case of a 33-Year-0ld Female Schizophrenic Patient Who Ingested a Kilogram of Metals: A Case Report
}

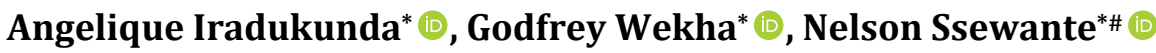 \\ School of Medicine, College of Health Sciences, Makerere University, Kampala, Uganda \\ Email: "nelson.ssewante1@gmail.com
}

How to cite this paper: Iradukunda, A., Wekha, G. and Ssewante, N. (2021) A Mysterious Case of a 33-Year-Old Female Schizophrenic Patient Who Ingested a Kilogram of Metals: A Case Report. Open Journal of Psychiatry, 11, 174-185.

https://doi.org/10.4236/ojpsych.2021.113014

Received: April 7, 2021

Accepted: July 4, 2021

Published: July 7, 2021

Copyright $\odot 2021$ by author(s) and Scientific Research Publishing Inc. This work is licensed under the Creative Commons Attribution International License (CC BY 4.0).

http://creativecommons.org/licenses/by/4.0/

\begin{abstract}
Introduction: Globally, 20 million people are affected by schizophrenia. In Uganda, the prevalence is reported to be 710 per 100,000 population. Unlike normal adults who are less likely to have foreign body ingestion, patients with mental illnesses such as schizophrenia are at an increased risk of both intentional and accidental foreign body ingestion. Therefore, health workers must be vigilant while assessing such patients not to miss out on the diagnosis as unwitnessed foreign body ingestion presents a diagnostic challenge. Observation: We received a 33-year-old female diagnosed with schizophrenia four years before this admission as a referral. She presented at MNRH A\&E with complaints of abdominal pain, non-bilious vomiting, and progressive weight loss. She had multiple admissions in private hospitals before her referral to MNRH where several investigations were done with inconclusive results. Upper GI endoscopy revealed multiple foreign bodies in the stomach. An erect abdominal $\mathrm{x}$-ray was then done to rule out distal gastrointestinal involvement and/or perforation. An emergency laparotomy was performed and over 170 different metallic objects of varying sizes were completely evacuated. She reported that she ingested them in response to the compelling auditory hallucinations but had no intention of self-harm. Conclusion: Foreign body ingestion presents a diagnostic challenge in adults. The various impairments among mentally ill patients put them at an increased risk hence the need for suspicious diagnostic evaluation of those presenting with abdominal symptoms. Both health workers and families have a role to play in the prevention of such life-threatening emergencies.
\end{abstract}

\section{Keywords}

Schizophrenia, Foreign Bodies, Mental Health, Abdominal Pain,

*All authors contributed equally to the development of this report.

\#Corresponding author. 


\section{Introduction}

Schizophrenia is a severe chronic mental disorder [1] [2]. Globally, 20 million people are affected [1]. In Uganda, the prevalence is reported to be 710 per 100,000 population with Central Uganda having the highest cases at 26 per 10,000 population [3]. Common presenting complaints include hallucinations, delusions, disorganized speech and behavior, and negative symptoms such as diminished emotional expression, avolition, anhedonia, alogia, and asociality [2] [4]. Its peak of onset is in adolescence and early adulthood but rarely occurs in pre-school children [2] [5].

Schizophrenia is associated with considerable morbidity and overall poor quality of life as it may affect educational and occupational performance [1]. Likewise, people with schizophrenia are 2 - 3 times more likely to die early than the general population [2]. Foreign body ingestion is also common among this population and this may be intentional or accidental [6] [7]. Intentional foreign bodies can be suicidal or as part of the spectrum of the disease symptoms for example due to auditory commanding hallucinations or an illusion in which the patient perceives the object as food [4].

More than $69 \%$ of schizophrenic patients worldwide are not receiving appropriate care according to the World Health Organisation (WHO) and 90\% of these are in Sub-Saharan Africa [1]. The low Social Economic Status (SES) of this region makes access to mental health services difficult which explains this trend [1] [8]. Generally, proper treatment using both biomedical and psychosocial models is effective. Patients who retain their employment, and reasonable social support are more likely to have better outcomes than their counterparts. Additionally, Stigma associated with schizophrenia and other mental health disorders is a major perpetuating factor for the disease and often leads to drifting away from home and social withdrawal [9]. Therefore, this should be addressed throughout patient management.

The limited access to primary care, follow up and continuous psychosocial support among mentally ill patients makes identification of related complications difficult. Moreover, even with enough literature evidencing the risk of foreign body ingestion among mentally ill patients, unwitnessed cases remain a diagnostic challenge to health workers and everyone involved in patient care. Therefore, we report this mysterious case with an aim to implore health workers attending to mentally ill patients presenting with abdominal symptoms to hold foreign body ingestion with a high index of suspicion.

\section{Case Report}

BP is a 33-year-old female who was admitted at Mulago National Referral Hos- 
pital (MNRH) Accident and Emergency Department as a referral from Mengo Hospital upon relatives' request. She presented with a four months history of abdominal pain and a two weeks history of non-bilious vomiting. These symptoms were associated with progressive weight loss that had been ongoing for almost a year and occasional disturbances in bowel habits but no associated fevers, night sweats, or cough (Table 1). Apparently, she had several admissions in

Table 1. Sociodemographic characteristics and clinical features of the patient.

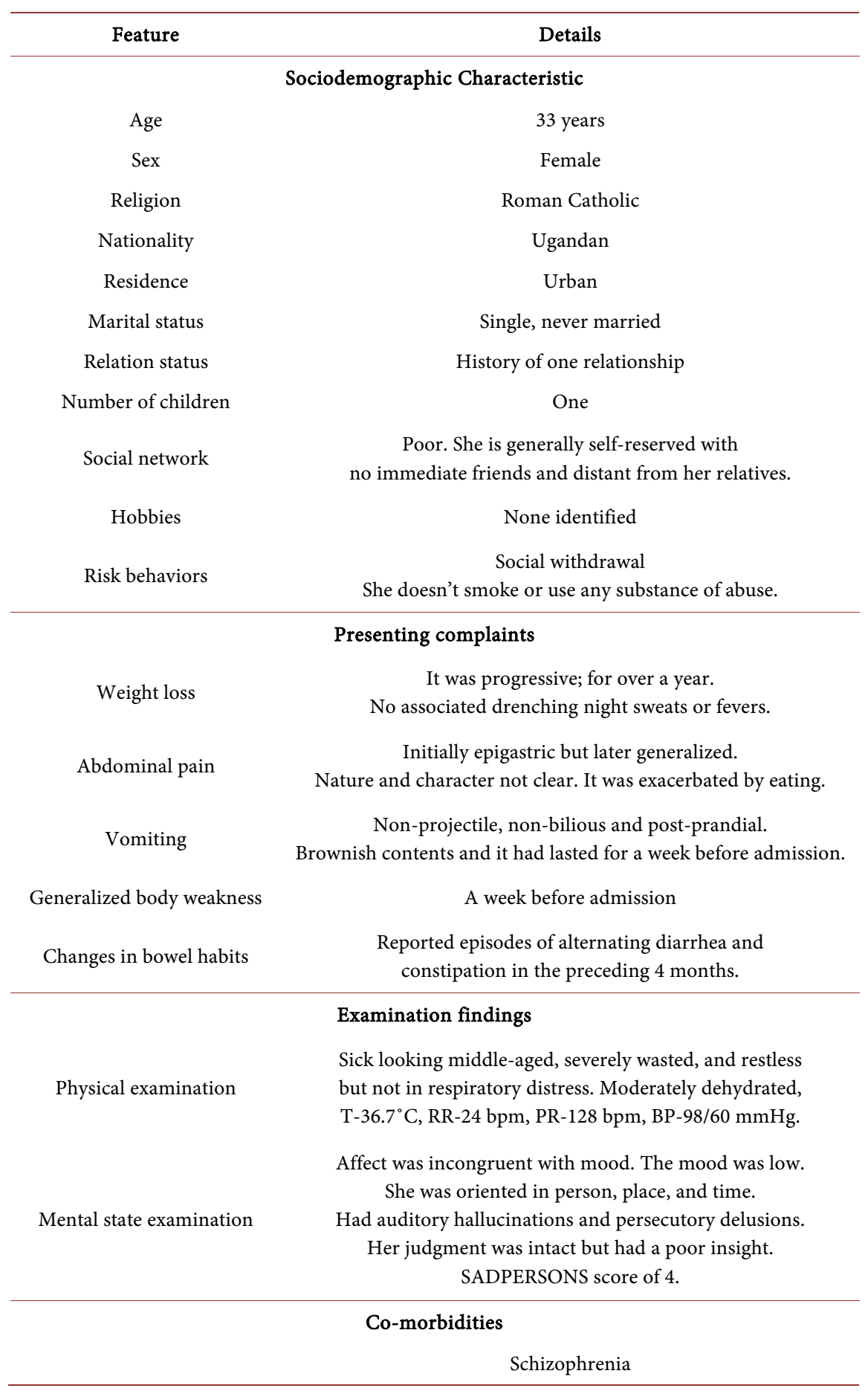


different health units for the same complaints. She was investigated for Helicobacter pylori, Malaria, Typhoid, and Human Immunodeficiency Virus (HIV) but with negative results and no improvement upon management (Table 2). However, a day before this admission an Upper Gastro-intestinal endoscopy (Figure 1) and an erect abdominal $\mathrm{x}$-ray (Figure 2) were done upon relatives' request results of which revealed multiple metallic foreign bodies filling up the stomach (Pyloric antrum and body) causing gastric outlet obstruction (GOO). Notably still is that three nails and one tower clip were recovered from her bra in an attempt to take the $\mathrm{x}$-ray. Her uncle reported that most of these objects she could have picked from his store at home since he is an electrician.

Her past psychiatric history revealed a diagnosis of schizophrenia which was made 4 years before this admission from Butabika National Referral Hospital where she was managed as an Out-Patient on antipsychotics for six weeks. Unfortunately, documents detailing this were not carried along with the patient and therefore, we couldn't ascertain the antipsychotics she was given. However, it was reported that following the initiation of this therapy relatives noted that she spent most of her time sleeping and showed no improvement. For this reason, they sought a second opinion from a family friend, a Psychologist who upon the patient's reassessment advised discontinuation of antipsychotics. He, however; recommended patient counseling which they did but was not helpful. Unfortunately, no further interventions have been tried since then.

She has no known chronic medical illness, food or drug allergies, and no history of major trauma, surgery, or blood transfusion.

Table 2. Investigations done.

\begin{tabular}{|c|c|}
\hline Investigation & Results \\
\hline Complete Blood counts & $\begin{array}{l}\text { WBC: Neutrophilia. } \\
\text { RBC: Hb-11.9 g/dL with normal HCT, MCH and MCHC } \\
\text { PLT: } 432 \times 10^{3} / \mathrm{uL}\end{array}$ \\
\hline \multicolumn{2}{|l|}{ Malaria screen } \\
\hline 1) $\mathrm{RDT}$ & Negative \\
\hline 2) Blood smear & No malaria parasites seen \\
\hline Typhoid test & Non-reactive \\
\hline Helicobacter pylori & Negative \\
\hline HIV screen & Non-reactive \\
\hline COVID-19 & Negative \\
\hline Upper GI endoscopy & $\begin{array}{l}\text { Normal oropharynx, hypopharynx, and esophagus. Competent } \\
\text { gastroesophageal sphincter, retained gastric contents, multiple nails, } \\
\text { and other metals filling the stomach about one kilogram (Figure 1). }\end{array}$ \\
\hline Erect Abdominal x-ray & $\begin{array}{l}\text { Homogeneous opacity in the abdominal cavity } \\
\text { consistent with metallic foreign bodies (Figure 2) }\end{array}$ \\
\hline
\end{tabular}

WBC: White Blood Cells; RBC: Red Blood Cell; Hb: Hemoglobin; HCT: Hematocrit; MCH: Mean Corpuscular Hemoglobin; MCHC: Mean Corpuscular Hemoglobin Concentration; RDT: Rapid diagnostic test; PLT: Platelets. 


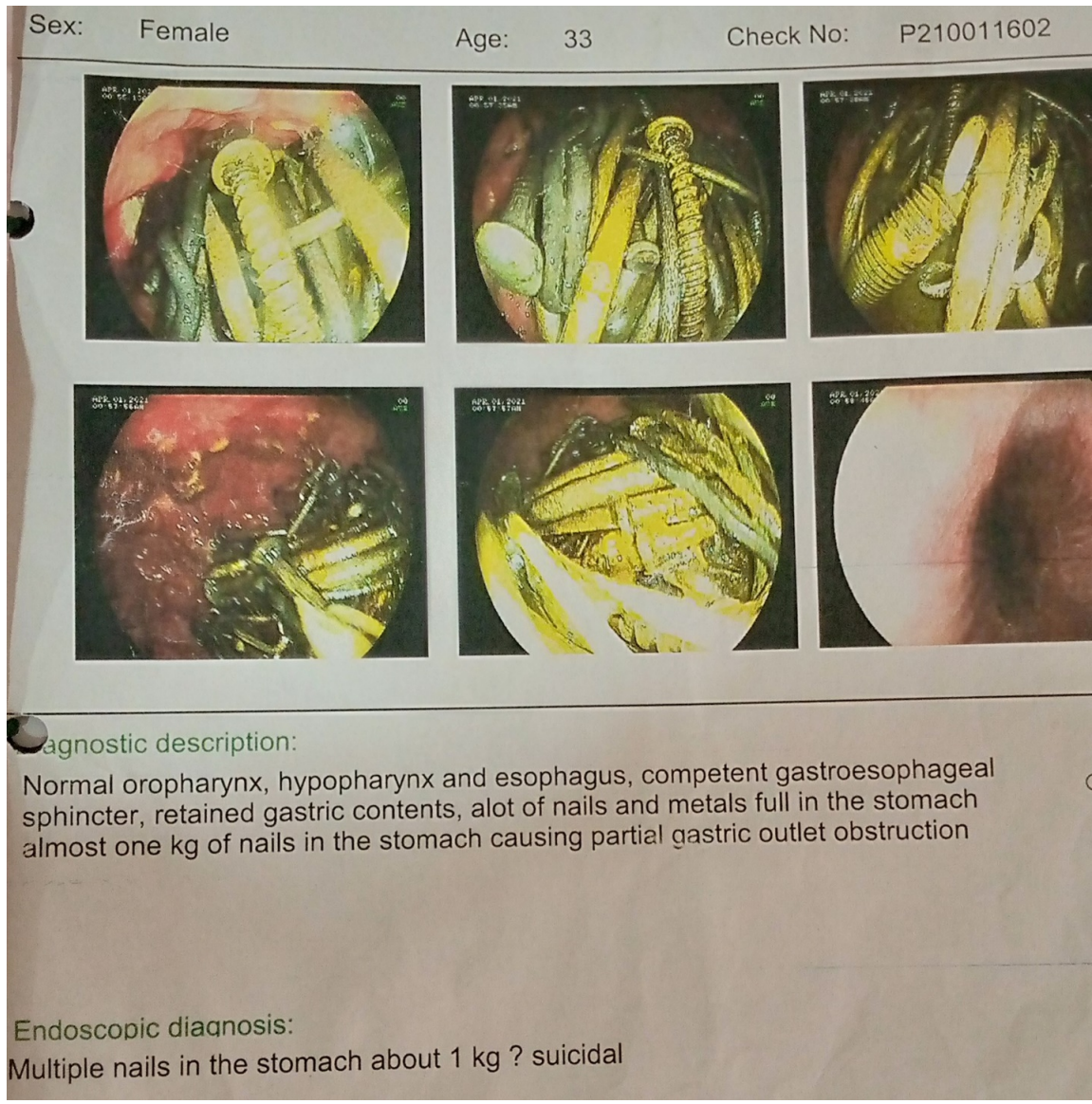

(a)
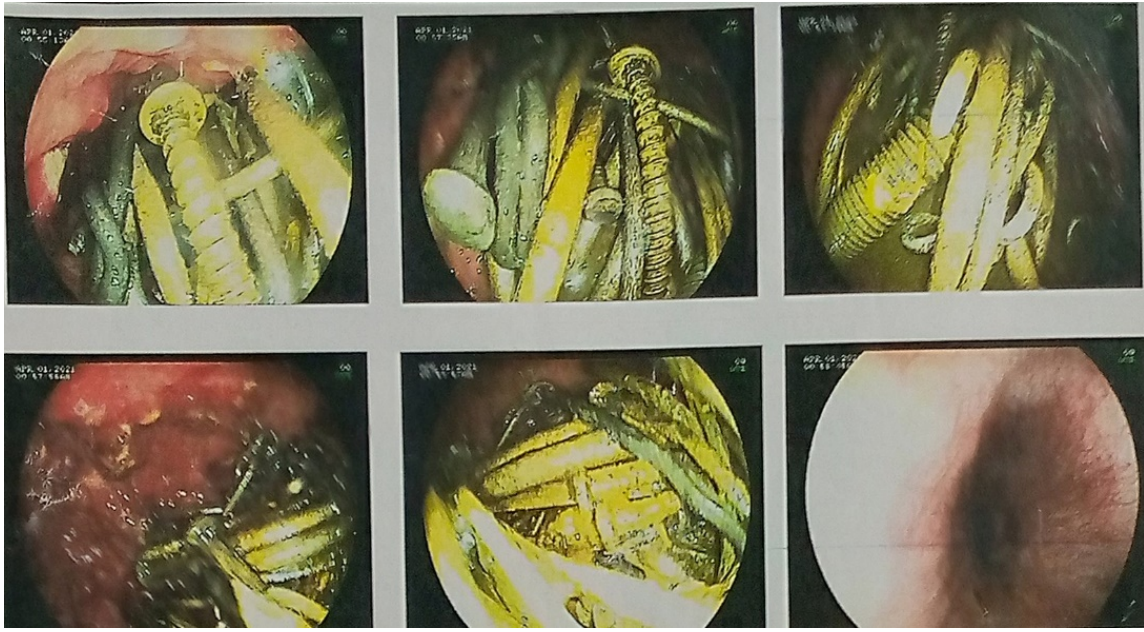

(b)

Figure 1. Upper GI endoscopy. (a) With description; (b) Focused image.

She had normal developmental milestones and started school at the age of 5 years. However, in her primary 2 and 4, she lost her mother and father respectively. Since then, she has lived in different homes including her grandparents', her uncle's in Uganda, and her aunt's in Kenya. Prior to this admission, she was living at her sister's place who is employed in a private Pharmacy, and most 


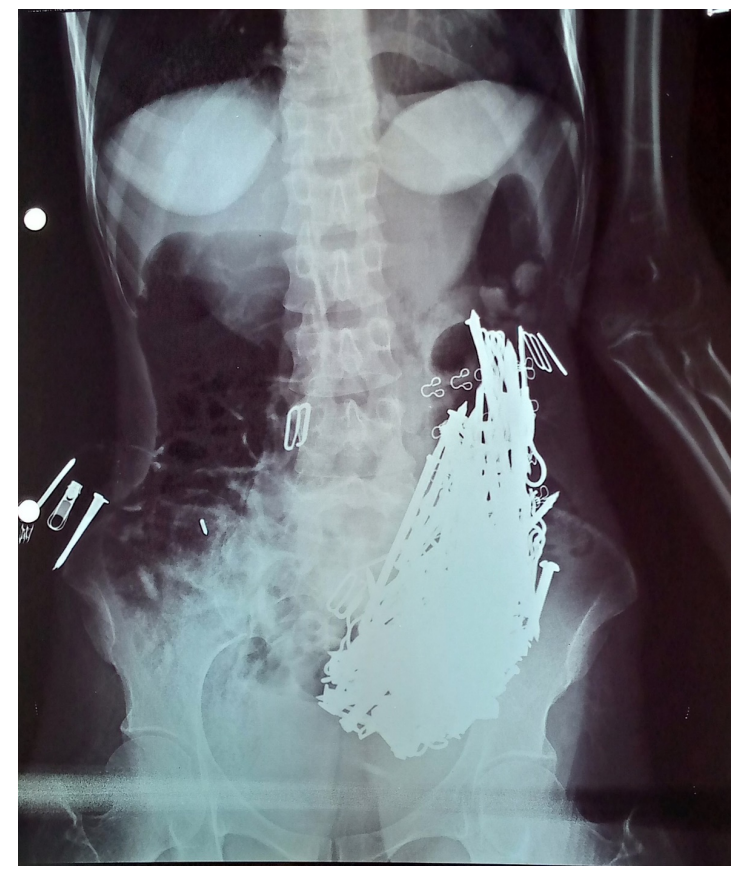

Figure 2. A plain erect abdominal radiograph film (X-ray).

times she is left alone at home without supervision. She finished her Standard Eight from Kenya, Uganda Certificate of Education, Uganda Advanced Certificate of Education, and a Diploma in Hotel management in 2002, 2007, 2009, and 2013 respectively. As per the admission day, she was single but had a 7 years old child who lives with one of her relatives. In her entire life, she reported having engaged in one relationship. This was with the father of her child whom she met while pursuing her diploma in Jinja, Uganda but unfortunately, she later found out that he was married to another woman which led to their dramatic breakup. Upon completion of her Diploma, she got employed twice. However, she lost both jobs because of her mental illness. She reported no history of smoking or use of any substance of abuse.

A mental state exam on post-operative day one revealed a fairly groomed female although she appeared older than her stated age. She had reduced energy and did not maintain eye contact. Her affect was incongruent with her mood. Her mood was rather depressed. She had an organized and logical thought process. She reported having heard her uncle and sister discussing a plan of adding more poison in her food a day before her admission. She also reported hearing unfamiliar voices compelling her to ingest nails and other metals within her reach which she obeyed. She believed that her sister and uncle wanted to kill her and for that reason, she drifted away from home. However, there was no intention of self-mutilation or harm and she scored 4 points on a modified SAD PERSONS scale (Sex-0, Age-0, Depression-2, Previous attempt-0, Excessive Ethanol use-0, Rational thinking loss-0, Separated-1, organized plan-0, No social support-1, Stated future intent-0) for suicide risk. A cognitive exam revealed that she was oriented to person, place, and time. Her memory was intact but with 
mild impairment of attention and concentration. She lacked insight into her situation but her judgment was adequate.

On physical examination, she was fully conscious, sick-looking, unkempt, and severely wasted but not in distress. She was afebrile to touch with an axillary temperature of $36.7^{\circ} \mathrm{C}$, moderately dehydrated with a pulse rate of 128 beats per minute, respiratory rate of 24 breaths per minute, and blood pressure of 98/60 $\mathrm{mmHg}$. The abdomen was moderately distended moving with respiration and tender on palpation. Other examination findings were normal.

Upon admission and reassessment at MNRH, the patient was prepared for an emergency laparotomy. Intra-operatively, a midline incision was made on the anterior abdominal wall and found a distended stomach with a nail perforating through its wall. A $5 \mathrm{~cm}$ gastrostomy incision was then made $4 \mathrm{~cm}$ away from the greater curvature and found over 170 metallic foreign bodies of varying sizes and types. These were completely evacuated and are shown in Figure 3. Gastric lavage was done using normal saline and Decasan before repairing the defect, closing the gastrostomy incision, and closing the anterior abdominal wall. The patient was then transferred to the Post Anesthetic Care Unit (PACU) for post-operative monitoring from where she was subsequently moved to the surgery ward under the care of the surgical team and a psychiatrist. Patient had an uneventful recovery post operatively. However, she had an episode of hypotention on post operative day 3 which was managed with intravenous fluids. On post operative day 7 , she was discharged through mental health unit under the care of her relatives who were briefed on the significance of social support among patients living with mental illness.

\section{Discussion}

Ingestion of foreign bodies is a common finding in children [6] [7] [10]. However, in adults, they are uncommon and therefore present a diagnostic challenge unless witnessed. Ingestion of foreign bodies occurs either accidentally or intentionally with the latter commonly motivated by suicidal ideations, attention-seeking in borderline personality patients, or as a result of compelling hallucinations to ingest them [7] [11]. It can also happen in illusions when the patient perceives these objects as food [4]. Much as our patient reported that she knew these were not food, she went on to ingest them in response to auditory hallucinations (commanding in nature) she vividly experienced. In 2017, a similar case was reported from Bangladesh with a 32-year-old male with schizophrenia and cannabis use who presented with a history of ingesting foreign bodies and after endoscopic confirmation, 29 objects were removed from his stomach by gastrostomy [6]. The Uniqueness of our case lies in the overwhelming number of objects ingested and the fact that this was neither witnessed nor passively reported by the patient before diagnosis. Over 170 metallic objects of varying sizes were evacuated from her stomach, the closest to this being that of a 24-year-old male who ingested over 50 metals [12]. 


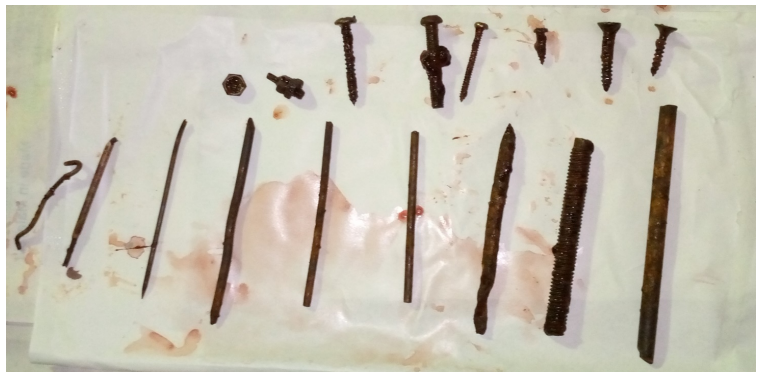

(a)

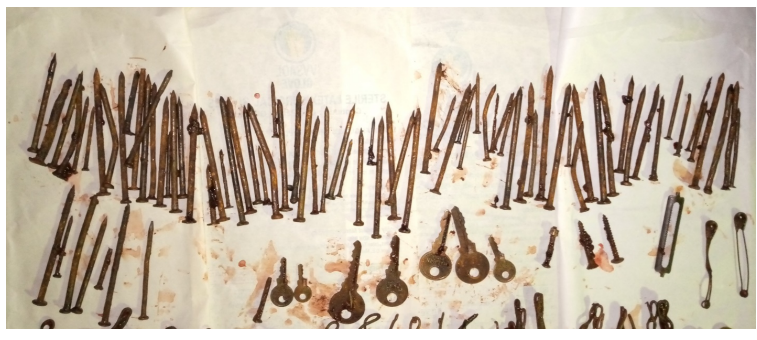

(b)

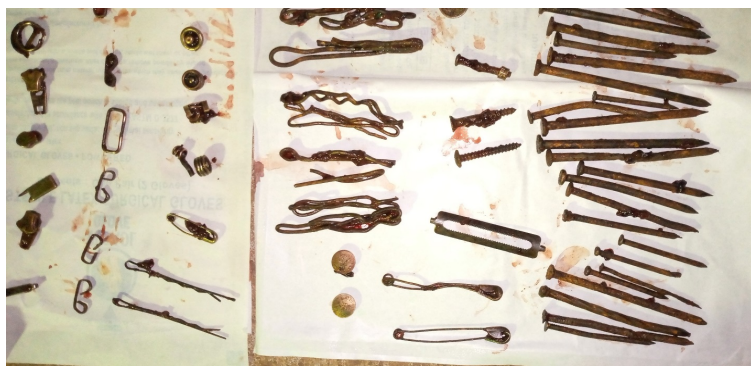

(c)

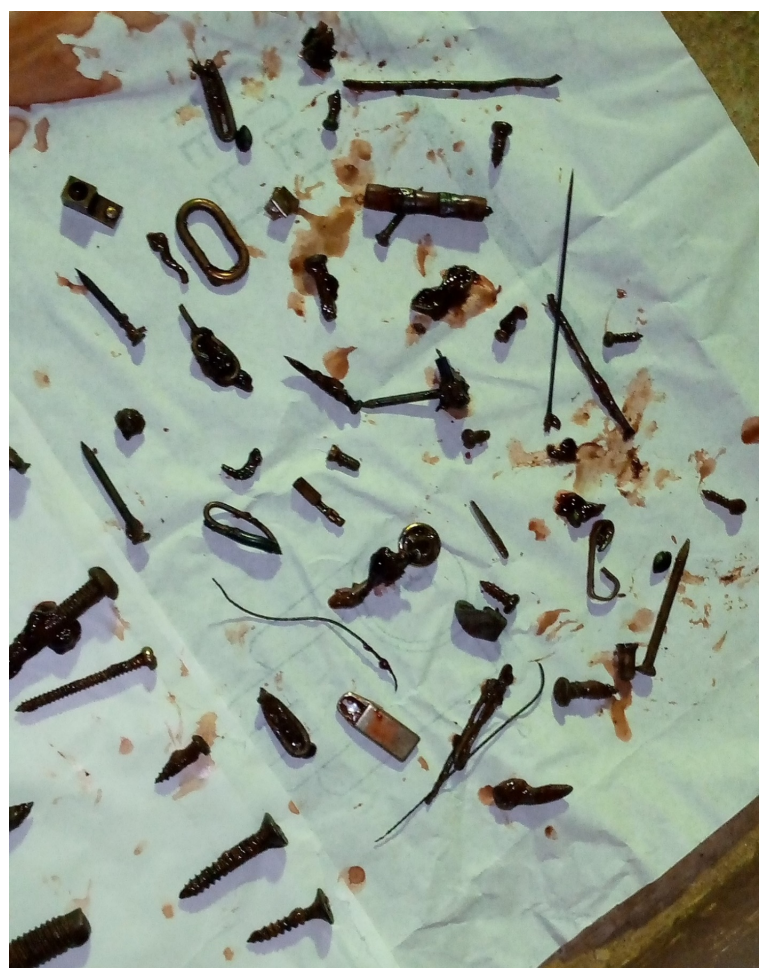

(d) 


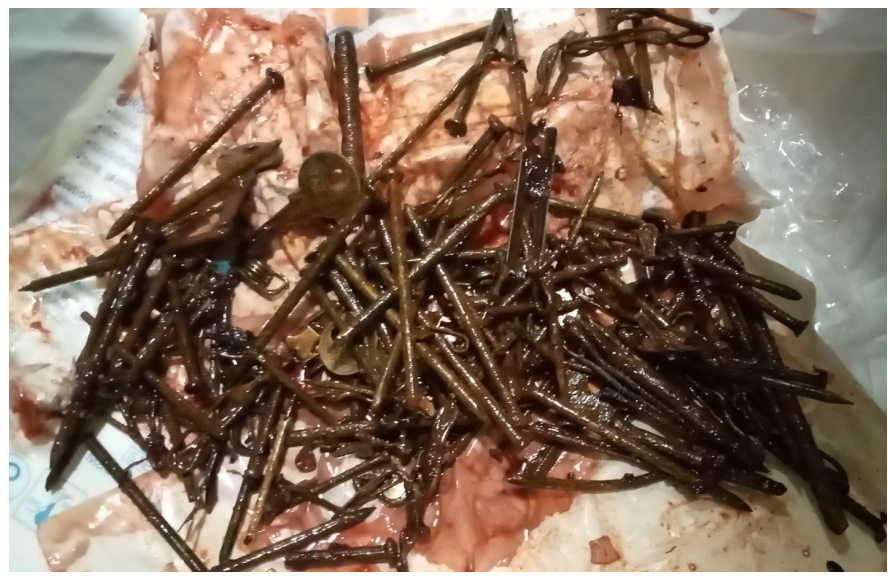

(e)

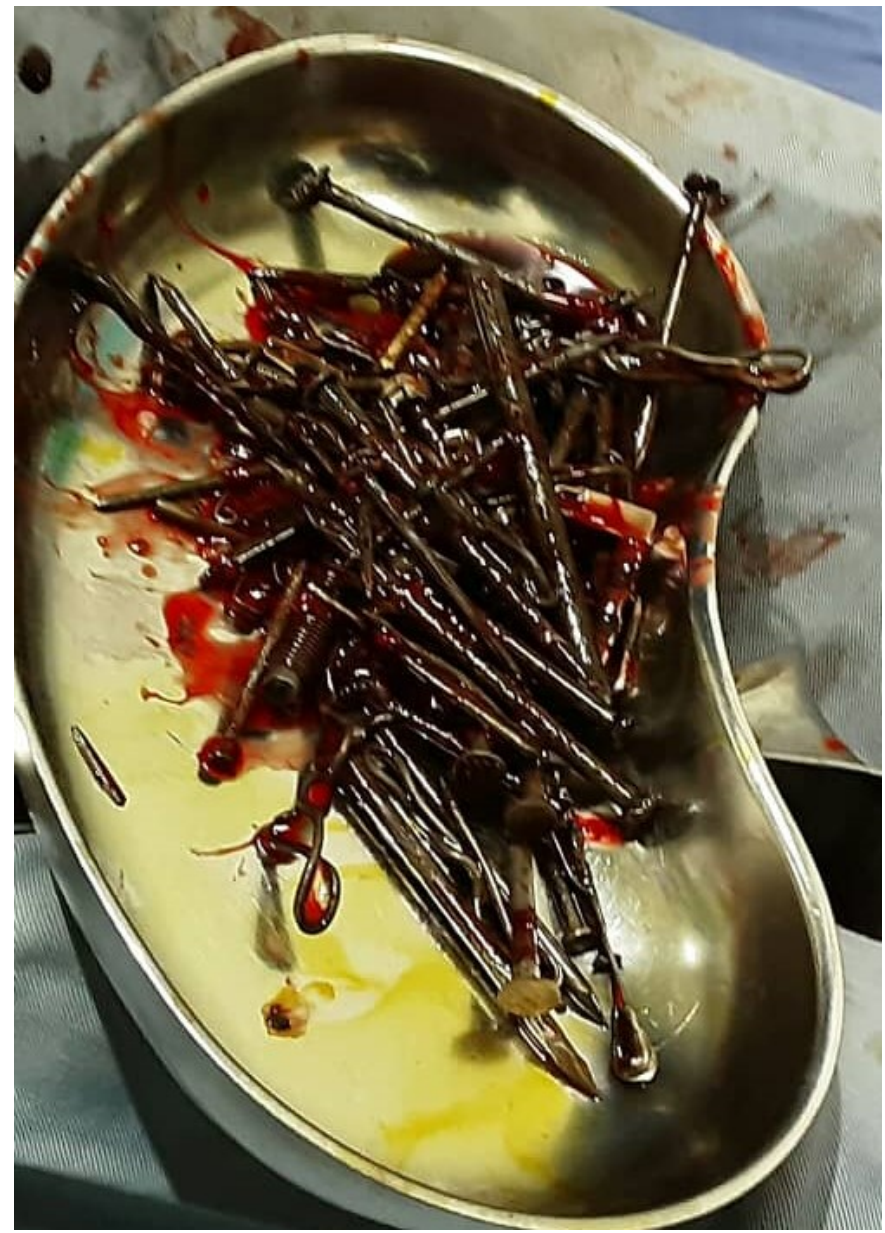

(f)

Figure 3. Foreign bodies after their removal from the stomach. In total, 93 nails of varying sizes, 16 screws, 26 binding wires, 8 broken metallic rods, 7 keys, 6 staples, 4 zips, 3 safety pins, 2 dry cells, 2 hair clips, 1 sewing needle, 1 grater machine cutting end and many small unidentified metal objects were found in the stomach. (a) Metal rods and small screws; (b) Nails, keys, screws, safety pins and cutting edge of grater machine; (c) Nails, binding wires, safety pins. hair clipers, staples, etc; (d) Sewing needle and multiple other small metals; (e) Metals just before sorting; (f) Metals as they appeared on a kidney dish in the operation theatre. 
Sharp objects are painful to swallow and are therefore not commonly encountered in emergency departments (EDs) unless there is a definitive motive for self-harm. Literature described a possibility that patients whose motive is not self harm cover sharp objects with a piece of paper before their ingestion [7]. Such history was not revealed by our patient and so it is not clear how she ingested almost a kilogram of metals including nails, sewing needles, safety pins, and keys among others successfully without injuring her esophagus. She reported no history of GIT bleeding and upper GI endoscopy reported normal esophageal lumen without any features of strictures or erosions as would otherwise be expected (Figure 1). The more the compelling hallucinations persisted the more she continued to ingest these metals which resulted in gastric outlet obstruction. Since this was not witnessed it was very hard to diagnose. On multiple previous admissions she had, doctors were thinking in lines of peptic ulcer disease, typhoid, malaria, severe acute malnutrition, Human Immunodeficiency Virus (HIV), intraabdominal malignancy, and disseminated tuberculosis but none had thought of a foreign body.

It is worth noting that this behavior is often repetitive and only surgical evacuation may not be enough [13]. In a retrospective study involving patients seen at accidents and emergency department between September 2015 and December 2017 with foreign body ingestion, 11 patients were followed after discharge and it was observed that most of the patients who had ingested sharp objects were presenting again at the emergency department with the same complaints since these were mostly deliberate self-harm [13]. This patient ingested multiple sharp objects including a sewing needle, staple wires, keys, safety pins, nails among others but insisted that she had no motive for self-harm. It, however, remains to be noted during follow-up whether this is the case as she seemed to be protective against this practice given, she had not disclosed anything related to this before the discovery of some of these metals from her bra during the attempt to take $\mathrm{x}$-ray images. She reported that these could have been put by "her friends" she made while away from home and she denied putting them herself. This is in relation to a case of a 24-year-old male with paranoid schizophrenia who presented with complaints of a chronic headache but later on assessment confirmed to have foreign bodies in his stomach [12]. Laparotomy and gastrostomy were performed and removed over 50 metallic objects. This 24 -year-old patient had initially denied ingesting them deliberately but later conceded to have done it to relieve his boredom [12].

Initial psychiatric assessment of our patient resulted in the diagnosis of Schizophrenia however treatment approach was poor. While caring for these patients, a family-centered approach should be applied. Family members need to have a better understanding of the dynamics of the illness to be in a position to provide psychological and social support. Therefore, information regarding available treatment approaches, adverse effects profile, prognosis as well as their roles should be discussed to promote drug adherence and overall treatment outcomes. In this case, family-centered care was not employed as evidenced by the 
fact that just after six weeks of initiation of therapy they sought a second opinion because of perceived treatment failure and concerns of oversleeping. Unfortunately, this attempt resulted in rather futile outcomes as patient counseling was not successful and the patient continued to deteriorate.

Family dysfunction has been described as a risk factor for poor prognosis in schizophrenic patients [14]. Just like in other mental illnesses, patients with schizophrenia have varying levels of cognitive impairment and so need to be monitored closely. This patient lost her parents at a young age, lived in multiple families, and had a failed relationship. It is likely that she has never considered herself part of a functional family. Additionally, we also found out that she was being left home alone throughout her illness without supervision. A patient with schizophrenia who reportedly showed no improvement on antipsychotics left unattended to is a risk to self.

As described by Ming Chen et al. homeless patients with schizophrenia are more likely to have a history of family disruption, poor adherence to health care, and multiple emergency visits and hospitalization [9]. Our case is in agreement with this finding. With the nature of her family setting and lack of psychosocial support and proper treatment, she drifted away from home where she probably started ingesting some of these objects before returning home. Family conference was conducted which in addition to information about her condition, outlined the role of health workers and family members in her management. On her post operative day 7 , she was discharged in a stable condition through mental health unit for re-evaluation and further management.

\section{Conclusion}

Foreign body ingestion remains a rare finding in adults and so presents a diagnostic challenge. However, in mentally ill patients, a vast majority of derangements in cognition puts them at risk of both accidental and intentional ingestion of foreign bodies. This should be held with a high index of suspicion in those presenting with abdominal symptoms. Both health workers and family members have definitive roles to play in the prevention of such emergencies to reduce morbidity and mortality among this population.

\section{Conflicts of Interest}

The authors declare no conflicts of interest regarding the publication of this paper.

\section{References}

[1] Schizophrenia [Internet] (2019) World Health Organization (WHO). https://www.who.int/news-room/fact-sheets/detail/schizophrenia

[2] Kim, M. (2016) Understanding the Etiology and Treatment Approaches of Schizophrenia: Theoretical Perspectives and Their Critique. Open Journal of Psychiatry, 6, 253-261. https://doi.org/10.4236/ojpsych.2016.64030

[3] Alitubeera, H.P., Kadobera, D., Sheila, N., Lukwata, H. and Ario, A.R. (2021) Pre- 
valence and Trends of Common Mental and Neurological Disorders in Uganda, 2012-2016: Analysis of National Surveillance Data. Research Square [Internet]. https://doi.org/10.21203/rs.3.rs-17580/v1

[4] Diagnostic and Statistical Manual of Mental Disorders (2013) In: Diagnostic and Statistical Manual V [Internet], 5th Edition, American Psychiatric Association, Arlington, 87-122. https://www.psychiatry.org/

[5] Hor, K. and Taylor, M. (2010) Review: Suicide and Schizophrenia: A Systematic Review of Rates and Risk Factors. Journal of Psychopharmacology, 24, 81-90. https://doi.org/10.1177/1359786810385490

[6] Islam, M.S., Hasan, M.M., Debnath, C.R., Uddin, M.A., Biswas, N., Kabir, K.M., et al. (2017) Exceptional Multiple Foreign-Body Ingestion by a Patient with Schizophrenia. Mymensingh Medical Journal, 26, 194-197.

[7] Abraham, B. and Alao, A.O. (2005) An Unusual Foreign Body Ingestion in a Schizophrenic Patient: Case Report. The International Journal of Psychiatry in Medicine, 35, 313-318. https://doi.org/10.2190/7AE8-3AV0-W3UA-TKV4

[8] Kumar, S., Sudhakar, S., Sajatovic, M. and Levin, J.B. (2020) Antipsychotic Medication in Sub-Saharan Africa: A Systematic Literature Review. Journal of Clinical Psychopharmacol, 40, 541-552. https://doi.org/10.1097/JCP.0000000000001282

[9] Chen, I.M., Wu, K.C.C., Chien, Y.L., Chen, Y.H. and Lee, S.T. (2015) Missing Link in Community Psychiatry: When a Patient with Schizophrenia Was Expelled from Her Home. Journal of the Formosan Medical Association, 114, 553-557. https://doi.org/10.1016/j.jfma.2012.05.001

[10] Chantal, Gyebre, Y.M., Goueta, A., Priva, Ouedraogo, B., Sereme, M., Zamtako, O. and Ouoba, K. (2016) Unusual Foreign Body of Oropharynx. International Journal of Otolaryngology and Head \& Neck Surgery, 5, 189-194. https://doi.org/10.4236/ijohns.2016.55030

[11] Al-Faham, F.S.M. and Al-Hakkak, S.M.M. (2020) The Largest Esophageal Foreign Body in Adults: A Case Report. Annals of Medicine and Surgery, 54, 82-84. https://doi.org/10.1016/j.amsu.2020.04.039

[12] Kobiela, J., Mittlener, S., Gorycki, T., Lachinski, A.J. and Adrych, K. (2015) Vast Collection of Foreign Bodies in the Stomach Presenting as Acute Gastrointestinal Bleeding in a Patient with Schizophrenia. Endoscopy, 47, E356-E357. https://doi.org/10.1055/s-0034-1392611

[13] Robertson, A.R. (2019) Self-Harm by Sharp Foreign Body Ingestion. Suicide and Life-Threatening Behavior, 49, 735-738. https://doi.org/10.1111/sltb.12474

[14] Hashemian, P. and Sedaghati, M.E. (2016) Evaluation of Family Dysfunction in Patients with Schizophrenia and Bipolar I Disorder. Journal of Biosciences and Medicines, 4, 1-5. https://doi.org/10.4236/jbm.2016.42001 